\title{
High reliability of measure of diaphragmatic mobility by radiographic method in healthy individuals
}

\author{
Rossana V. Saltiel ${ }^{1}$, Samantha T. Grams ${ }^{1}$, Aline Pedrini ${ }^{2}$, Elaine Paulin ${ }^{3}$
}

\begin{abstract}
Background: Diaphragmatic evaluation is crucial in clinical practice, and no studies have reported the intraand interobserver reproducibilities of the radiographic method to evaluate diaphragmatic mobility. Objective: To analyze the reliability of radiographic measurement as a method for assessing the mobility of the left and right hemidiaphragms. Method: Forty-two patients, who were waiting for cholecystectomy surgery, were evaluated relative to the following parameters: physical examination, pulmonary function and radiographic evaluation. The measure of mobility of each hemidiaphragm was randomly determined by two physical therapists at two different times. The intra- and interobserver reproducibilities of the measurements were determined by the intraclass correlation coefficient (ICC[2,1]) and the $95 \%$ confidence interval (CI). The Bland-Altman plot was also used. The level of significance was 5\%. Results: In the analysis of intra-observer reproducibility in radiographic evaluations of the left and right hemidiaphragms, ICC [2,1] indicated a "very high correlation" for both observer A (ICC $[2,1]=0.99, \mathrm{p}<0.001$ and $\operatorname{ICC}[2,1]=0.97, \mathrm{p}<0.001$, respectively) and observer B (ICC $[2,1]=0.99, p<0.001$ and ICC $[2,1]=0.99 p<0.001$, respectively). In the analysis of interobserver reproducibility, the ICC $[2,1]$ indicated a "very high correlation" for the 1 st and 2 nd radiographic evaluations of the right hemidiaphragm $(\mathrm{ICC}[2,1]=0.98$ and $\mathrm{ICC}[2,1]=0,99$, respectively, $\mathrm{p}<0.001)$ and left hemidiaphragm $(\mathrm{ICC}[2,1]=0.98$ and ICC $[2,1]=0.99$, respectively, $\mathrm{p}<0.001$ ). Conclusion: The intra and interobserver tests of the radiographic measure of mobility of the left and right hemidiaphragms showed high reliability.
\end{abstract}

Keywords: physical therapy; diaphragm; radiographic; reproducibility of the tests.

\section{HOW TO CITE THIS ARTICLE}

Saltiel RV, Grams ST, Pedrini A, Paulin E. High reliability of measure of diaphragmatic mobility by radiographic method in healthy individuals. Braz J Phys Ther. 2013 Mar-Apr; 17(2):128-136. http://dx.doi.org/10.1590/S1413-35552012005000076

\section{Introduction}

Functional evaluation of the diaphragm muscle is essential in clinical practice because the mobility of this muscle within the thoracoabdominal complex is responsible for much of the pulmonary ventilation ${ }^{1-3}$. However, direct evaluation of this muscle is practically inaccessible because, unlike other skeletal muscles, the diaphragm has a complex shape, and its anatomical location presents challenges to measurements of its ability to generate force and movement ${ }^{4}$.

Some imaging methods can be used to evaluate the mobility of the diaphragm, such as fluoroscopy, ultrasound, computerized axial tomography, magnetic resonance imaging and thoracic radiography ${ }^{5-9}$. Fluoroscopy has been considered the most reliable method (gold standard) for quantitative assessments of the range of craniocaudal diaphragmatic motion. Although it is a simple method that permits observation of two hemidiaphragms and the analysis of regional pulmonary ventilation, fluoroscopy has some disadvantages such as high patient exposure to ionizing radiation, diaphragm visualization through a single plane and the need for corrective calculations ${ }^{6}$. In contrast, the radiographic method is easy to use, non-invasive, inexpensive and can be performed in most hospitals and clinics because radiography equipment is commonly found in these environments. Although radiography exhibits the same disadvantages as fluoroscopy, the patient is exposed to a lower radiation dose.

Moreover, the radiographic method for the evaluation of diaphragmatic motion provides clinical practices with the ability to reliably measure the functionality of the diaphragm muscle and is valid for health care professionals that seek to establish functional diagnoses and/or monitor treatment progression. These factors are important because diaphragmatic muscle dysfunction can be observed in various clinical situations, such as in patients with muscular dystrophy or phrenic nerve injury, 
in patients undergoing thoracic and/or abdominal surgeries and in patients with chronic obstructive pulmonary disease $\mathrm{e}^{10-12}$.

Several studies have been performed to evaluate diaphragmatic mobility by the radiographic method $^{7,13-17}$; however, there is no examination standardization, and there is also a lack of studies to verify the reliability of the method. A reliable instrument is known to be able to measure the same parameters at different times, regardless of whether the same evaluator performs the measurements, thus ensuring the reliability of the results. Therefore, reliability studies are highly necessary to detect changes in the measured parameters and to ensure the reduction of measurement errors ${ }^{18}$.

Despite the importance of assessing the reliability of instruments of measurement, no previous studies have confirmed the intra- and interobserver reproducibilities of the radiographic method for evaluations of diaphragmatic mobility; similarly no previous studies have investigated the reliability of radiographic measurement as a method for the evaluation of left and right hemidiaphragmatic mobility in adults. Therefore, the objective of this study was to analyze the reliability of radiographic measurement as a method for assessing the right and left hemidiaphragmatic mobility in adults.

\section{Method}

\section{Characterization of the research}

The study was characterized as an observational and cross-sectional evaluation of reproducibility tests that sought to assess the degree of agreement between mobility measurements of the right and left hemidiaphragms via the radiographic method. Radiographs were selected randomly and were evaluated by two different and blinded observers. The evaluations were repeated by the same observers under similar conditions at one week after the initial evaluation.

\section{Population and sample}

Forty-two patients who were hospitalized in the Surgery Ward of the São José Dr. Homero de Miranda Gomes Regional Hospital (Hospital Regional de São José Dr. Homero de Miranda Gomes - HRHMG), in the city of São José, SC, Brazil, from September 2010 to August 2011 were selected for the study. These patients had been admitted for cholecystectomy.

The inclusion criteria for participants were as follows: verification of normal pulmonary function, age between 18 and 70 years old, and not suffering from cognitive or neurological disease. Patients excluded from the study included those whose chest radiographs showed poor visualization of the diaphragmatic cupules and thus showed no difference between the inspiratory and expiratory moments and/ or those whose radiographs showed abnormalities. The study was approved by the Research Ethics Committee of the HRHMG under protocol no. 027/11, and all participants signed an informed consent form.

\section{Research procedures}

In the Surgical Clinic of the HRHMG, the participants underwent physical examinations for the measurements of cardiorespiratory signs and anthropometric variables, assessments of pain and evaluations of pulmonary function. All tests were performed by a single examiner. For chest radiographs, the patients were sent to the Department of Radiology at the same hospital.

\section{Evaluation of cardiorespiratory signs and anthropometry}

Oxygen saturation $\left(\mathrm{SpO}_{2}\right)$ and resting heart rate (HR) were measured with a pulse oximeter (Linde Model MD300). The respiratory rate (RR) per minute was evaluated by observing the movement of the thorax during respiration.

A mechanical anthropometric scale coupled with a stadiometer (Filizola model 31) was used for body mass measurements. The participants were instructed to wear light clothing, remove their shoes when stepping onto the scale and stand erect while facing forward. The stadiometer coupled to the scale was used to measure height, and the participants were measured without shoes, with heels together and while standing as upright as possible. After obtaining the anthropometric values (body mass and height), the body mass indices (BMI) were calculated from the following equation: body mass $/ \mathrm{height}^{2}\left(\mathrm{~kg} / \mathrm{m}^{2}\right)$.

\section{Assessment of pain}

Pain intensity was measured with the Visual Analogue Scale (VAS). This scale has drawings of facial expressions that are each associated with a numerical scale from zero to ten in order to represent pain; in this scale, a happy face and number zero indicated the absence of pain, and a sad face and number ten represented unbearable pain ${ }^{19}$. The patients were asked whether they felt pain and to classify the level. 


\section{Pulmonary function test}

The pulmonary function test was performed with the use of a digital portable spirometer (ndd Medical Technologies EasyOne TM Diagnostic Spirometer) that had been previously calibrated according to the methods and criteria recommended by the American Thoracic Society ${ }^{20}$. We evaluated the forced vital capacity (FVC), forced expiratory volume in the first second $\left(\mathrm{FEV}_{1}\right)$ and the $\mathrm{FEV}_{1} / \mathrm{FVC}$ ratio. During the test, at least three acceptable and two reproducible assessments were obtained (e.g. the two largest FVC and $\mathrm{FEV}_{1}$ values should have a difference of $\leq$ $0.15 \mathrm{~L}$ ). The highest values obtained for each of the spirometric variables were considered. These values were expressed in absolute values and as percentages of predicted normality according to those determined by Pereira et al. ${ }^{21}$. The criteria for a normal pulmonary test consisted of $\mathrm{FVC}$ and $\mathrm{FEV}_{1}$ of $\geq 80 \%$ of predicted values and $\mathrm{FEV}_{1} / \mathrm{FVC}$ of $\geq 0.7$.

\section{Radiographic evaluation of diaphragmatic motion}

The mobility of the right and left hemidiaphragms was evaluated by chest radiography in the anteroposterior view. For the chest radiographs, the patients were referred to the Department of Radiology at the HRHMG and were positioned on a radioscopy table in the supine position. During the exams, a ruler with radiopaque markings was placed under the right hemithorax of patients near the thoracoabdominal transition, in a longitudinal alignment and in the craniocaudal direction. The radiographic exposures were obtained during maximal inhalations and exhalations by an experienced radiographer who was properly qualified to perform the test. Patients were instructed in advance by the physical therapist responsible for the project to achieve and sustain maximum respiratory efforts during the exams. The physical therapist monitored the acquisition of all radiographs. In an attempt to minimize possible methodological problems, the radiographic technique, the posture adopted by the individual during exposure as well as the verbal stimulation performed by the radiology technician were standardized in an attempt to obtain maximum diaphragmatic excursion in both the inspiratory and expiratory phases.

Quantifications of the radiographic measurements of right and left hemidiaphragmatic mobility were independently determined by two physical therapists (observers A and B) during two separate stages (first and second assessment) that were separated by an interval of one week. The same radiographs were analyzed in both the first and second assessments.
A third physical therapist randomly presented radiographic exams for evaluation by the observers and noted the results. Thus, observers A and B could not identify to which patient the radiographs belonged nor did they have access to the evaluation scores of the other observer. The results were analyzed after the completion of all reviews.

To determine the radiographic measurements, observers A and B used the method described by Toledo et al. ${ }^{7}$, in which radiographic images of the maximal inspiration and expiration of each patient were carefully overlapped to measure the diaphragmatic motion. In the maximal expiration radiographic images, the observers identified the highest point of the cupola of the right hemidiaphragm and drew a longitudinal line from this point. The intersection of this line with the hemidiaphragmatic cupola was used to define the measurement point at maximal inspiration. The mobility of the right hemidiaphragm was then determined by the distance between the points at the maximum inspiration and expiration with a Messen $150 \mathrm{~mm} / 6$ digital caliper (Figure 1). The same procedure was used to evaluate the mobility of the left hemidiaphragm.

A radiographic ruler was used to correct the amplitude determined by the divergence of the $\mathrm{X}$-rays and also as a reference for overlapping the images. To correct for the magnification of the images due to X-ray divergence, the observers measured the distance between two graduation points on the radiographic image that corresponded to $10 \mathrm{~mm}$. The corrected value of hemidiaphragm mobility was therefore obtained by the following formula: Corrected mobility $(\mathrm{mm})=$ mobility measurement $(\mathrm{mm}) \times 10(\mathrm{~mm}) /$ measured graduation of the ruler $(\mathrm{mm})^{7}$.

\section{Statistical analysis}

The data were analyzed with the SPSS Program for Windows, version 17.0, and they were tested with descriptive (mean and standard deviation) and inferential analyses. The Shapiro-Wilk test was used to verify the normality of the data.

The intra- and interobserver reproducibilities of the radiographic measurements of right and left hemidiaphragmatic mobility were determined by the Intraclass Correlation Coefficient of two routes with absolute agreement $\left(\mathrm{ICC}_{[2,1]}\right.$; two way random model, with absolute agreement) and the $95 \%$ confidence interval $(\mathrm{CI})$.

The ICC was interpreted as follows, according to the Munro classification system ${ }^{22}$ : little or no correlation for values between $0-0.25$, low correlation 
for values between $0.26-0.49$, moderate correlation for values of $0.50-0.69$, high correlation for values between $0.70-0.89$ and very high correlation for values between 0.90-1.00.

The Bland-Altman ${ }^{23}$ plot was also used to analyze inter- and intraobserver reproducibility to permit a better visualization of the correlation between individual measures.

Due to the non-parametric distribution of the data, the Wilcoxon Test was used to verify the differences between the mobilities of the right and left hemidiaphragms. The significance level adopted for statistical treatment was $5 \%(\mathrm{p}<0.05)$.

\section{- Results}

Initially, 52 participants were selected for the study; however, ten were excluded from the study due to a lack of high-quality radiographs. Of the 42 participants selected, 27 were female $(64.3 \%)$ and 15 were male $(35.7 \%)$; the mean age was $39.7 \pm 13.7$ years, and the mean BMI was 29.4 \pm 37.6 , thus classified as overweight. All participants were using analgesics and reported zero pain on the VAS.

The anthropometric characteristics and the values obtained in the pulmonary function tests of the participants are shown in Table 1.

There were no statistically significant differences in the mobility measurements of the right and left hemidiaphragms made by the observers at the two different evaluation periods. In the first assessment, the mobility values of the right (RH) and left hemidiaphragms ( $\mathrm{LH})$ when analyzed by observer A were $36.65 \pm 17.86$ and $35.12 \pm 18.82(\mathrm{p}=0.31)$, respectively, and when analyzed by observer $\mathrm{B}$, these values were $36.81 \pm 17.07$ and $35.50 \pm 18.15$ $(\mathrm{p}=0.36)$, respectively. In the second evaluation, observer A reported values of $36.53 \pm 17.81(\mathrm{RH})$ and $34.83 \pm 18.18(\mathrm{LH})(\mathrm{p}=0.24)$, and observer $\mathrm{B}$, values of $36.55 \pm 17.42(\mathrm{RH})$ and $35.15 \pm 18.30(\mathrm{LH})$ $(\mathrm{p}=0.33)$.

In the analysis of intraobserver reproducibility, the ICC indicated a very high correlation in the assessment of radiographic measurement of the right and left hemidiaphragms for both observer A $(\operatorname{ICC}[2,1]=0.99, \mathrm{p}<0.001$ and ICC $[2,1]=0.97, \mathrm{p}<0.001$, respectively) and observer $\mathrm{B}(\mathrm{ICC}[2,1]=0.99, \mathrm{p}<0.001$ and $\mathrm{ICC}[2.1]=0.99$, $\mathrm{p}<0.001$, respectively).

In the analysis of interobserver reproducibility, the ICC indicated a very high correlation for both the first and second radiographic evaluations of the right hemidiaphragm (ICC $[2,1]=0.98$ and ICC $[2,1]=0.99$, respectively, $\mathrm{p}<0.001$ ); similarly, a very high correlation was also indicated for both the first and second radiographic evaluations of the left hemidiaphragm (ICC $[2,1]=0.98$ and

Table 1. Anthropometric characteristics and pulmonary function variables of the study subjects.

\begin{tabular}{lc}
\hline \multicolumn{1}{c}{ Variables } & $\begin{array}{c}\text { Means } \pm \text { Standard deviation } \\
(\text { variation) }(\mathbf{n = 4 2})\end{array}$ \\
Age (years) & $39.7 \pm 13.5(21-68)$ \\
Body mass $(\mathrm{kg})$ & $75.3 \pm 19.4(44.0-141.0)$ \\
Height $(\mathrm{m})$ & $1.62 \pm 0.09(1.49-1.82)$ \\
BMI $\left(\mathrm{kg} \mathrm{m}^{-2}\right)$ & $29.4 \pm 37.6(17.6-51.8)$ \\
FVC $($ pred\%) & $92.97 \pm 15.8(80-135)$ \\
$\mathrm{FEV}_{1}($ pred\%) & $90.61 \pm 16.6(80-128)$ \\
$\mathrm{FEV}_{1} / \mathrm{FVC}($ pred\%) & $97.23 \pm 6.7(81-108)$ \\
\hline
\end{tabular}

The values are expressed as the mean \pm standard deviation (variation: minimum value - maximum value); $\mathrm{n}$ : number of individuals; $\mathrm{kg}$ : kilograms; m: meters; BMI: body mass index; FVC (\% predicted): estimated percentage of forced vital capacity; $\mathrm{FEV}_{1}(\%$ predicted): estimated percentage of forced expiratory volume in the first second.
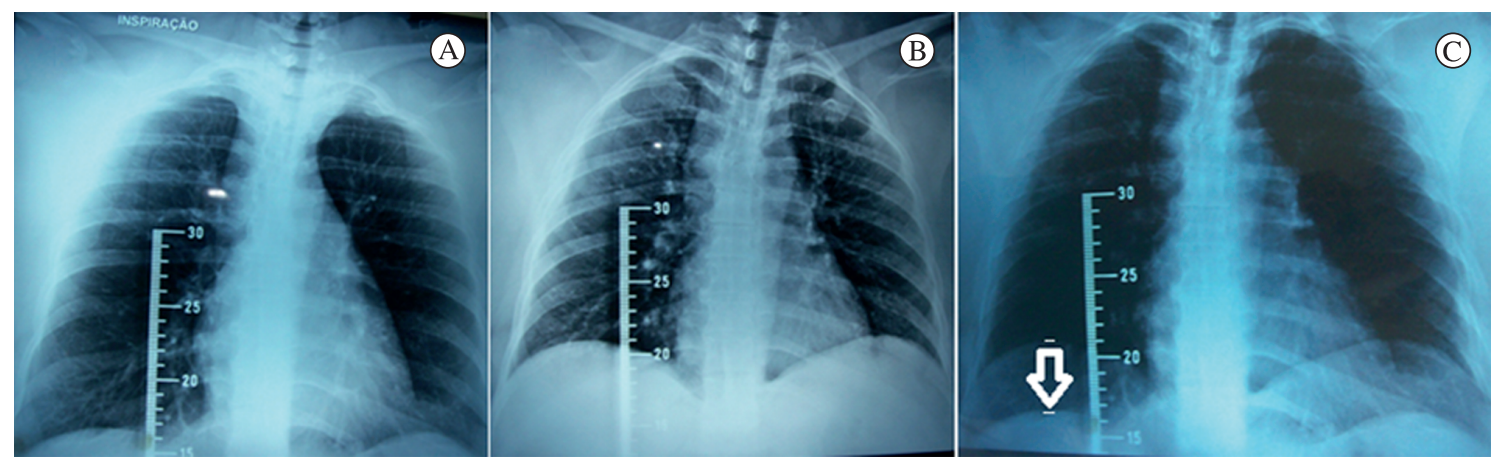

Figure 1. Anteroposterior view chest radiographs of the mobility of the right and left hemidiaphragms. A) Radiograph at maximal inspiration; B) Radiograph at maximal expiration; C) Overlay of images (expiration radiograph over the inspiration radiograph), using the radiographic image of the ruler as a reference. 
Table 2. Intraobserver and interobserver reproducibility of radiographic measurements of right and left hemidiaphragm.

\begin{tabular}{ccccc}
\hline Right hemidiaphragm & & ICC[2,1] & $\mathbf{9 5 \% ~ C I ~}$ & $\boldsymbol{p}$ \\
Intraobserver Reproducibility & Observer A & 0.99 & $0.99-1.00$ & $<0.001$ \\
& Observer B & 0.99 & $0.99-1.00$ & $<0.001$ \\
Interobserver Reproducibility & $1^{\text {st }}$ assessment & 0.98 & $0.97-0.99$ & $<0.001$ \\
& $2^{\text {nd }}$ assessment & 0.99 & $0.98-1.00$ & $<0.001$ \\
Left hemidiaphragm & & & $0.95-0.99$ & $<0.001$ \\
Intraobserver Reproducibility & Observer A & 0.97 & $0.98-1.00$ & $<0.001$ \\
Interobserver Reproducibility & Observer B & 0.99 & $0.96-0.99$ & $<0.001$ \\
& $1^{\text {st }}$ assessment & 0.98 & $0.99-1.00$ & $<0.001$ \\
\hline
\end{tabular}

$\mathrm{n}=$ number of individuals; $\mathrm{ICC}_{[2,1]}$ : intraclass correlation coefficient (two-way random effects model, with absolute agreement); $95 \% \mathrm{CI}: 95 \%$ confidence interval, $p$ : level of significance.

$\operatorname{ICC}[2,1]=0.99$, respectively, $p<0.001)$. The intraand interobserver reproducibilities of radiographic measurements of the right and left hemidiaphragms are shown in Table 2.

According to the Bland-Altman (Figure 2) plots, correlation is observed between the measures of mobility of the right and left hemidiaphragms that were obtained by each observer on two occasions (intraobserver agreement).

Also according to the Bland-Altman plots (Figure 3), correlation is observed between the mobility measurements of the right and left hemidiaphragms that were obtained by observers $\mathrm{A}$ and $\mathrm{B}$ in both the first and second radiographic evaluations (interobserver concordance).

\section{Discussion}

Both the intra- and interobserver evaluations of mobility measurements of the right and left hemidiaphragms, which were performed with a radiographic method in this study, are reproducible. This exam is easy to use in clinical practice, provides a reliable method with which to measure diaphragmatic mobility, and is valid for health care professionals who seek to establish functional diagnoses and/or monitor treatment responses. This is important because diaphragm muscle dysfunction can be observed in various clinical situations, including patients with muscular dystrophy, patients with phrenic nerve injuries, patients undergoing thoracic and/or abdominal surgeries and patients with chronic obstructive pulmonary disease $e^{9,10-12}$.

Reliable instruments are essential in clinical practice because the use of subjective methods could compromise the obtained results. Therefore, it is extremely important that any instrument or assessment method is evaluated with respect to its reliability in order to ensure that the measurement error is reduced and to detect changes in the measured parameter ${ }^{18}$.

The average mobility of the right hemidiaphragm was $36.6 \pm 17.5 \mathrm{~mm}$, a result similar to that found in a study by Toledo et al. ${ }^{7}$, in which the average value obtained in the radiographic evaluation of the mobility of the right hemidiaphragm was $34.8 \pm 17.0 \mathrm{~mm}$.

According to $\mathrm{Simon}^{24}$, most adults have a diaphragmatic excursion $\geq 30 \mathrm{~mm}$. Houston et al. ${ }^{25}$ reported that normal diaphragm mobility is $>20 \mathrm{~mm}$, and Gerscovich et al. ${ }^{26}$ reported similar results to those of Houston et al. ${ }^{25}$. Although the values of diaphragmatic motion observed in our study were considered normal, there are no studies in the literature that have described reference values for this variable. Moreover, there are no predictive equations for normal diaphragmatic mobility within the Brazilian population. However, it is crucial to understand the predictive value of this variable in order to optimize evaluations of diaphragmatic dysfunction and to enable the establishment of focused physical therapy.

There were large ranges of variation (in $\mathrm{mm}$ ) in the obtained minimum and maximum values, and such variations were also reported in other studies $8,6,24$. Simon et al..$^{13}$ observed a diaphragmatic value range from 0 to $85 \mathrm{~mm}$, Houston et al. ${ }^{25}$ observed a range from 23 to $97 \mathrm{~mm}$, Kantarci et al. ${ }^{27}$ observed a range from 25 to $84 \mathrm{~mm}$ and Boussuges et al..$^{8}$ observed a range from 36 to $92 \mathrm{~mm}$. 

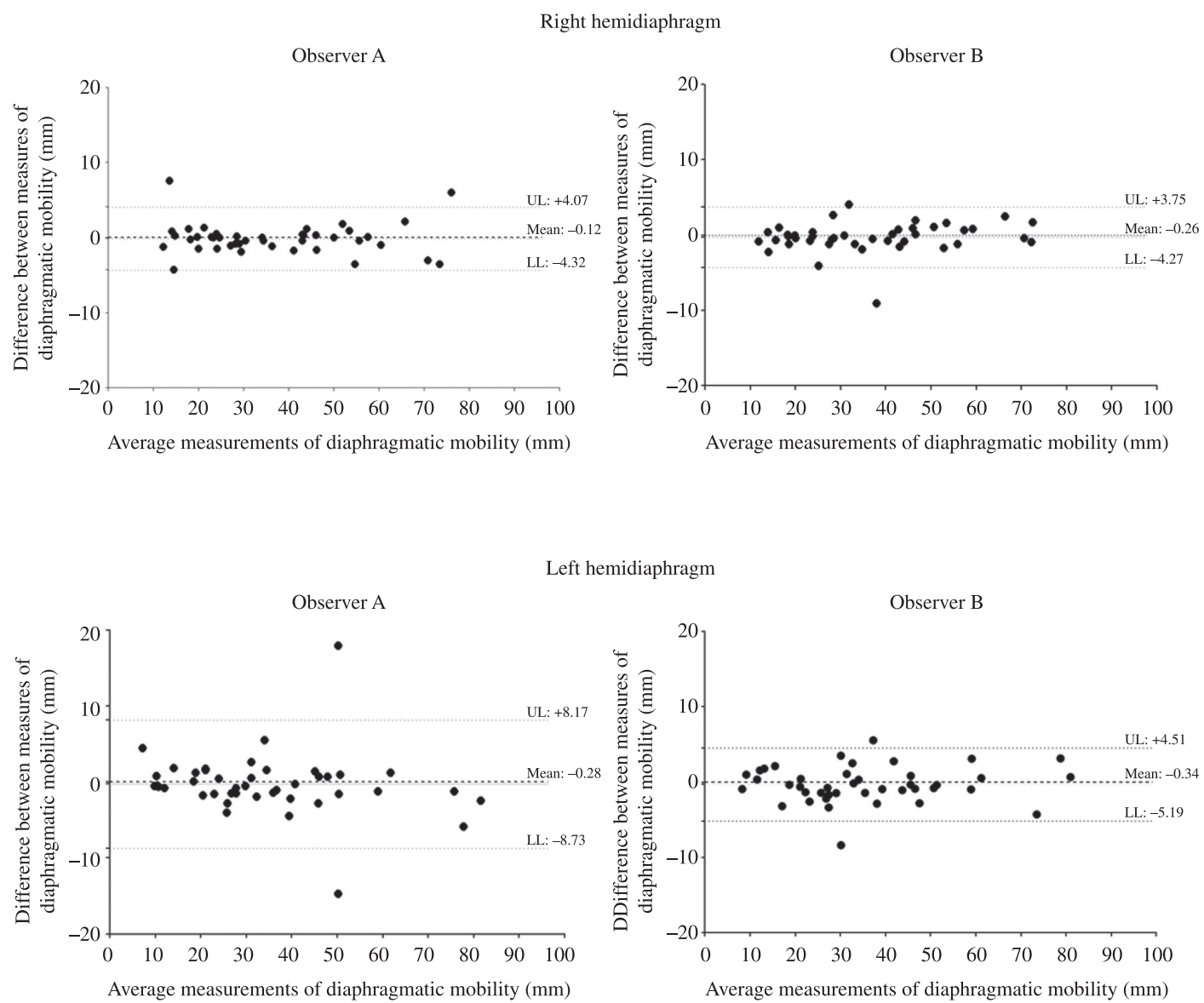

Figure 2. Bland-Altman plot for the analysis of the agreement between the measures of mobility of the right and left hemidiaphragms that were obtained by observer A and observer B in the first and second assessments (Intraobserver A agreement and intraobserver B agreement). OBSERVER A: X-axis: Average measures of diaphragmatic motion obtained in the first and second assessments by observer A for each participant (Measurement of observer A in the first evaluation + Measure of observer A in the second evolution / 2). Y-axis: Difference between the measures of diaphragmatic mobility obtained in the first and second assessments by the observer for each participant (Measurement of observer A in the second evaluation - Measurement of observer A in the first evaluation). OBSERVER B: Average measures of diaphragmatic motion obtained in the first and second assessments by observer $B$ for each participant (Measurement of observer B in the first evaluation + Measurement of observer B in the second evolution / 2). Y-axis: Difference between the measures of diaphragmatic mobility obtained in the first and assessments by the observer for each participant (Measurement of observer B in the second evaluation - Measurement of observer B in the first evaluation). UL: Upper limit. LL: Lower limit.

This large variability in the values of diaphragmatic mobility might be due to the patient BMI, which is a useful measure for assessments of excess body fat; according to the international classifications ${ }^{28}$, adults with a BMI between 25 and 29.9 are considered overweight. Obesity is known to hinder respiratory mechanics because a decrease in functional residual capacity due to chest compression results in an elevated diaphragm ${ }^{29}$. Thus, increased mechanical work is required for breathing and the diaphragm acts against the pressure of the distended abdomen ${ }^{30}$, which can limit its mobility. In the present study, only two participants were of normal weight, and most were classified as pre-obese, which leads us to believe that the observed average diaphragmatic mobility might have been higher if the average BMI of the participants was lower.

In addition to the BMI, age can also influence the variability of diaphragmatic mobility measurements. Some studies that investigated the use of radiographic techniques had large variations in participant age. Simon et al. ${ }^{13}$ conducted a study with 188 patients between the ages of 15 and 65 years old. Toledo et al. ${ }^{7}$ evaluated 51 patients between 15 and 71 years old. In studies performed by Singh et al. ${ }^{16}$ and Fernandes et al. ${ }^{17}$, the ages of the participants were also varied, but the variations were slightly lower than in the above-mentioned studies and ranged from 40 to 80 
Right hemidiaphragm
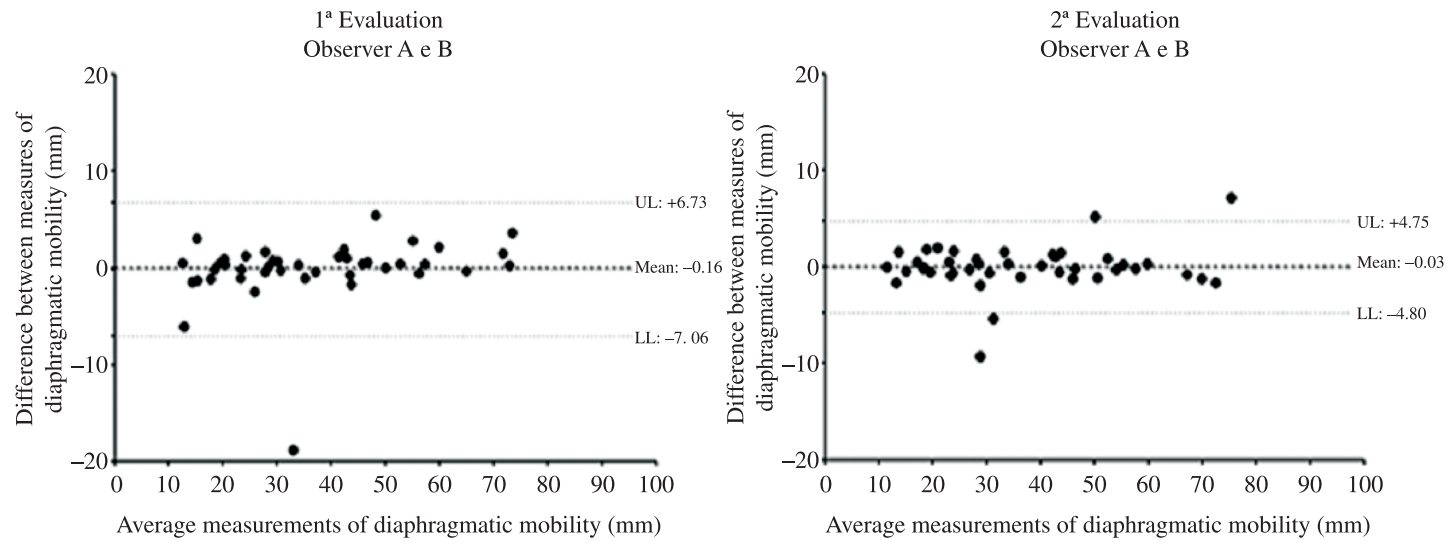

Left hemidiaphragm
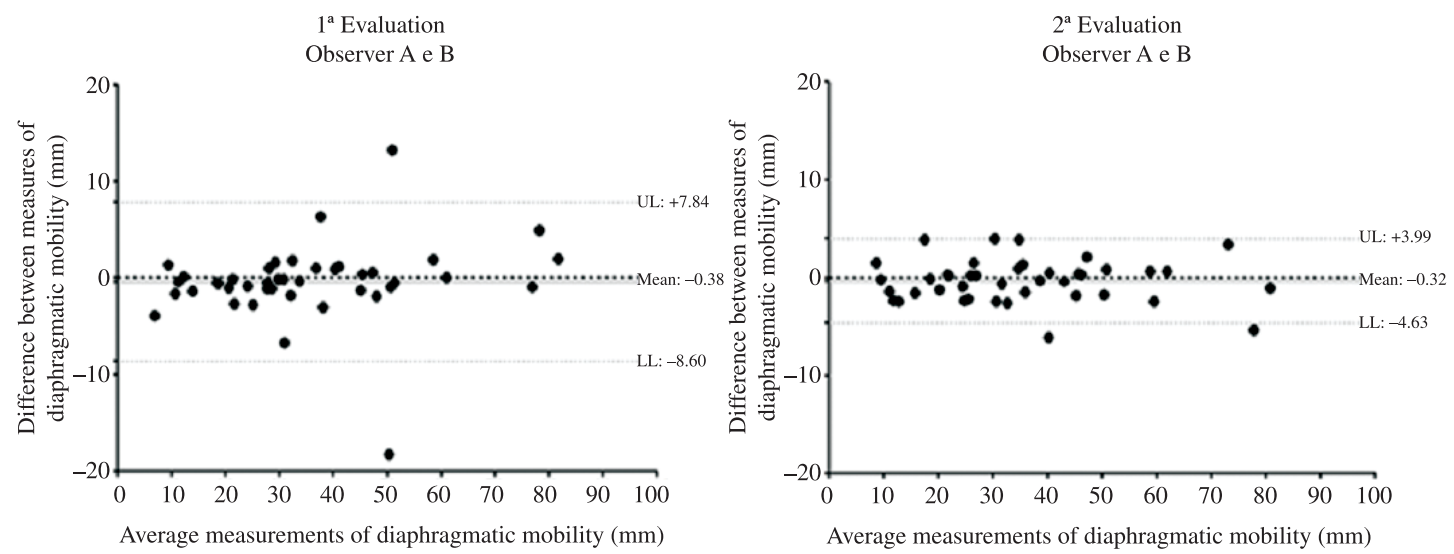

Figure 3. Bland-Altman plot for the analysis of the correlation between the measures of mobility of the right and left hemidiaphragms that were obtained by observers A and B (interobserver agreement) in the first and second evaluations. X-axis: Average measures of diaphragmatic motion obtained by observers A and B for each participant (Measurement of observer A + Measurement of observer B / 2). Y-axis: Differences between the measurements of diaphragmatic motion obtained by observers A and B for each participant (Measurement of observer B - Measurement of observer A). UL: Upper limit. LL: Lower limit.

and 53 to 70 years old, respectively. This variation was also observed in our study, a factor that might have affected the variability of the observed mobility results because older patients tend to have poorer functional pulmonary mechanics ${ }^{31}$ than younger patients. However, these data do not compromise the results of our study because our main objective was to determine the reproducibility of the measurements obtained with this method.

The ICC, a reliability test of the observers, was used to verify the reproducibility of measurements of diaphragmatic motion that were obtained via the radiographic method. This test indicated a very high correlation between the measurements obtained by a single observer (intraobserver) and by different observers (interobserver) for both the right and left hemidiaphragms. The mobility measurements of the right hemidiaphragm as determined by chest radiography were found to be reliable.

In the present study, the reproducibility of the radiographic method was not verified due to the excess radiation to which the participants would be exposed; therefore, we instead chose to evaluate the reproducibility of the measurements obtained by this method. Moreover, because the participants were admitted to the hospital, they were subjected to a series of routine tests and sometimes were unwilling to participate in the study evaluations, which limited the patient sample size. 
The present study is unprecedented; other studies have used chest radiography to assess mobility of the diaphragm but to date, none have analyzed the reliability of the measurements obtained by this method. Other factors that led us to choose the method for this study included the relative simplicity when compared to other methods for evaluations of diaphragmatic mobility, the ease of access to radiological equipment in hospitals and clinics, the ease of application, the low cost and the ability to evaluate both diaphragmatic cupolas.

\section{Conclusion}

The radiographic method was shown to be a reliable and reproducible instrument for direct evaluations of the mobility of the right and left hemidiaphragms, according to both intra- and interobservational evaluations. This technique is easy to use in clinical practice and provides a reliable method with which to measure the extent of diaphragmatic mobility.

\section{References}

1. Reid WD, Dechman G. Considerations when testing and training the respiratory muscles. Phys Ther. 1995;75(11):971-82.

2. Anraku M, Shargall Y. Surgical Conditions of the Diaphragm: Anatomy and Physiology. Thorac Surg Clin. 2009;19(4):419-29. http://dx.doi.org/10.1016/j. thorsurg.2009.08.002

3. Yamaguti WP, Claudino RC, Neto AP, Chammas MC, Gomes AC, Salge JM, et al. Diaphragmatic Breathing Training Program Improves Abdominal Motion During Natural Breathing in Patients With Chronic Obstructive Pulmonary Disease: A Randomized Controlled Trial. Arch Phys Med Rehab. 2012;93(4):571-77. http://dx.doi. org/10.1016/j.apmr.2011.11.026

4. Mccool FD, Tzelepis GE, Hoppin FG. Inspiratory pump performance: a pressure flow volume framework. Thorax. 1995;85:1463-78.

5. Houston JG, Fleet M, Cowan MD, Mcmillan NC. Comparison of ultrasound with fluoroscopy in the assessment of suspected hemidiaphragmatic movement abnormality. Clin Radiol. 1995;50(2):95-8. http://dx.doi. org/10.1016/S0009-9260(05)82987-3

6. Gierada DS, Slone RM, Fleishman MJ. Imaging evaluation of the diaphragm. Chest Surg Clin N Am. 1998;8(2):237-80.

7. Toledo NSG, Kodaira SK, Massarollo PCB, Pereira OI, Mles S. Right hemidiafragmatic mobility: assessment with US measurement of craniocaudal displacement of left branches of portal vein. Radiology. 2003;228:389-94. http://dx.doi.org/10.1148/radiol.2282011554
8. Boussuges A, Gole Y, Blanc P. Diaphragmatic Motion Studied by M-Mode Ultrasonography: Methods, Reproducibility, and Normal Values. Chest. 2009;135(2):391-400. http://dx.doi.org/10.1378/ chest.08-1541

9. Roberts HC. Imaging the Diaphragm. Thorac Surg Clin. 2009;19:431-50. http://dx.doi.org/10.1016/j. thorsurg.2009.08.008

10. Ayoub J, Cohendy R, Prioux J, Ahmaidi S, Bourgeois JM, Dauzat M, et al. Diaphragm moviment before and after cholecystectomy: a sonographic study. Anesth Analg. 2001;92(3):755-61. http://dx.doi. org/10.1213/00000539-200103000-00038

11. Maish MS. The diaphragm. Surg Clin N Am. 2010;90(5):955-68. http://dx.doi.org/10.1016/j. suc.2010.07.005

12. Kang HW, Kim TO, Lee BR, Yu JY, Chi SY, Ban HJ, et al. Influence of Diaphragmatic Mobility on Hypercapnia in Patients with Chronic Obstructive Pulmonary Disease. J Korean Med Sci. 2011;26(9):1209-13. http://dx.doi. org/10.3346/jkms.2011.26.9.1209

13. Simon G, Bonnell J, Kazantzis G, Waller RE. Some radiological observations on the range of movement of the diaphragm. Clin Radiol. 1969;20(2):231-3. http://dx.doi. org/10.1016/S0009-9260(69)80181-9

14. Braun NMT, Arora NS, Rochester DF. Force-length relationship of the normal human diaphragm. J Appl Physiol. 1982;53(2):405-12.

15. Walsh JM, Webber CL, Fahey PJ, Sharp JT. Structural change of the thorax in chronic obstructive pulmonary disease. J Appl Physiol. 1992;72(4):1270-8.

16. Singh B, Eastwood PR, Finucane KE. Volume displaced by diaphragm motion in emphysema. J Appl Physiol. 2001;91(5):1913-23.

17. Fernandes M, Cukier A, Feltrim MIZ. Efficacy of diaphragmatic breathing in patients with chronic obstructive pulmonary disease. Chron Resp Dis. 2011;8(4):237-44.

18. Kimberlin CL, Winterstein AG. Validity and reliability of measurement instruments used in research. Am J Health Syst Pharm. 2008;65(23):2276-84. http://dx.doi. org/10.2146/ajhp070364

19. Carvalho DS, Kowacs PA. Avaliação da intensidade da dor. Migrâneas cefaléias. Obesity. 2006;9(4):164-8.

20. Miller MR. Series “ATS/ERS task force: Standardisation of lung function testing". Standardisations of spirometry. Eur Respir J. 2005;26:319-38. http://dx.doi.org/10.1183/ 09031936.05.00034805

21. Pereira CAC, Rodrigues SC, Sato T. Novos valores de referência para espirometria forçada em brasileiros adultos de raça branca. J Bras Pneumol. 2007;33(4):397-06. http:// dx.doi.org/10.1590/S1806-37132007000400008

22. Munro BH. Statistical methods for health care research. 3rd ed. New York: Lippincott Williams \& Wilkins; 1997.

23. Bland JM, Altman DG. Statistical methods for assessing agreement between two methods of clinical measurement. Lancet. 1986;327(8476):307-10. http:// dx.doi.org/10.1016/S0140-6736(86)90837-8 
24. Simon G. Principles of chest X-ray diagnosis. Am J Phys Med. 1972;51(1):42.

25. Houston JG, Morris AD, Howie CA, Reid JL, McMillan N. Technical report: quantitative assessment of diaphragmatic movement - a reproducible method using ultrasound. Clin Radiol. 1992;46(6):405-7. http://dx.doi.org/10.1016/ S0009-9260(05)80688-9

26. Gerscovich EO, Cronan M, McGahan JP, Jain K, Jones CD, McDonald C. Ultrasonographic evaluation of diaphragmatic motion. J Ultrasound Med. 2001;20(6):597-604.

27. Kantarci F, Mihmanli I, DemireL MK, Harmanci K, Akman C, Aydogan F, et al. Normal diaphragmatic motion and the effects of body composition: determination with m-mode sonography. J Ultrasound Med. 2004;23(2):255-60.

28. World Health Organization - WHO. Obesity: preventing and managing the global epidemic. Geneva: WHO; 2000. Technical report series, n. 894.
29. Enzi G, Baggio B, Vianello A. Respiratory disturbances in visceral obesity. Int J Obesity. 1990;14(26).

30. Zerah F, Harf A, Perlemunter L. Effects the obesity on respiratory resistence. Chest. 1993;103(5):1470-6. http:// dx.doi.org/10.1378/chest.103.5.1470

31. Zaugg M, Lucchinetti E. Respiratory function in the elderly. Anesth Clin North Am. 2000;18(1):47-58. http:// dx.doi.org/10.1016/S0889-8537(05)70148-6

\section{Correspondence}

\section{Elaine Paulin}

Universidade do Estado de Santa Catarina (UDESC)

Centro da Ciência da Saúde e do Esporte (CEFID)

Departamento de Fisioterapia

Rua Pascoal Simone, 358, Coqueiros

CEP 88080-350, Florianópolis, SC, Brasi

e-mail: elaine.paulin@udesc.br 